\title{
Species identification of genus Bifidobacterium based on partial HSP60 gene sequences and proposal of Bifidobacterium thermacidophilum subsp. porcinum subsp. nov.
}

\author{
Lin Zhu, Wei Li and Xiuzhu Dong \\ State Key Laboratory of Microbial Resources, Institute of Microbiology, Chinese Academy of \\ Sciences, Beijing 100080, P. R. China
}

Correspondence

Xiuzhu Dong

dongxz@sun.im.ac.cn

\begin{abstract}
Sequence homology of partial $60 \mathrm{kDa}$ heat-shock protein (HSP60) genes was analysed for 50 Bifidobacterium strains that represent 12 Bifidobacterium species and subspecies with validly published names. Sequence similarities were $96 \cdot 5-100 \%$ within the same species, $95 \cdot 5-97 \%$ at the subspecies level and 80-96\% (mean, 88\%) at the interspecies level among the 10 Bifidobacterium species. Hence, the HSP60 gene was a more accurate tool for species identification within the genus Bifidobacterium than 16S rDNA. Two new Bifidobacterium strains isolated from piglet faeces were shown to be closely related to the thermophilic bifidobacterial group, based on 16S rDNA sequence analysis: strain P3-14 ${ }^{\top}\left(=\right.$ AS $1.3009^{\top}=$ LMG $\left.21689^{\top}\right)$ exhibited $97 \cdot 9 \%$ similarity to Bifidobacterium boum JCM $1211^{\top}, 97 \cdot 2 \%$ similarity to Bifidobacterium thermacidophilum AS $1.2282^{\top}$ and $97 \%$ similarity to Bifidobacterium thermophilum JCM $1207^{\top}$. However, higher levels of DNA-DNA relatedness (83\%) and HSP60 gene sequence similarity ( $97 \%$ ) were determined between $B$. thermacidophilum AS $1.2282^{\top}$ and strain $\mathrm{P} 3-14^{\top}$, indicating a closer relationship between them. The new strains differed from B. thermacidophilum AS $1.2282^{\top}$ in some phenotypic characteristics, such as growth at a lower temperature $\left(46.5^{\circ} \mathrm{C}\right)$, as well as different sugar-fermentation patterns. Hence, a novel Bifidobacterium subspecies, Bifidobacterium thermacidophilum subsp. porcinum subsp. nov., is designated.
\end{abstract}

Bifidobacteria are obligately anaerobic bacteria and a member of the commensal intestinal microflora of humans and animals. Currently, the genus Bifidobacterium comprises over 30 species with validly published names, one of which also contains subspecies (Scardovi, 1986; Lauer, 1990; Biavati \& Mattarelli, 1991; Biavati et al., 1991; Crociani et al., 1996; Meile et al., 1997; Dong et al., 2000; Hoyles et al., 2002; Jian \& Dong, 2002). Conventional identification and classification of Bifidobacterium species have relied heavily on carbohydrate-fermentation patterns, which have been demonstrated to be strain-specific, rather than species-specific (Roy \& Ward, 1990).

Abbreviation: HSP, heat-shock protein.

The GenBank/EMBL/DDBJ accession numbers for the partial HSP60 gene and $16 \mathrm{~S}$ rDNA sequences of Bifidobacterium species and the complete 16S rDNA sequence of Bifidobacterium thermacidophilum subsp. porcinum reported in this study are AY166508-AY166575 and AY148470, respectively.

A list of Bifidobacterium strains used in this study and GenBank accession numbers for their HSP60 and 16S rRNA gene sequences is available as supplementary material in IJSEM Online.
$16 \mathrm{~S}$ rDNA homology analysis has been demonstrated to be a powerful and accurate method to determine phylogenetic relationships among bacteria, including generic relationships (Olsen et al., 1994; Stackebrandt \& Goebel, 1994). Sequence similarity levels among Bifidobacterium species ranged from 93 to $99 \%$ and were even greater than $99 \%$ within five groups (Miyake et al., 1998); this is too high to distinguish between Bifidobacterium species.

DNA-DNA hybridization has been acknowledged to be a superior method to elucidate relationships between closely related taxa, such as species. Bifidobacterial members within a species generally exhibited DNA-DNA reassociation values of $>70 \%$ (Lauer \& Kandler, 1983). However, this is a laborious and inconvenient method to identify an unknown isolate.

Transaldolase gene sequence-based PCR-denaturing gradient gel electrophoresis (PCR-DGGE) patterns have also been used to differentiate bifidobacterial species isolated from humans (Requena et al., 2002); however, this method failed to discriminate Bifidobacterium catenulatum from Bifidobacterium angulatum. 
The highly conserved $60 \mathrm{kDa}$ heat-shock protein (HSP60) has been considered to be another useful phylogenetic marker and sequence comparisons of its gene have been used for species identification and phylogenetic analysis of the genera Staphylococcus (Kwok et al., 1999) and Bartonella (Marston et al., 1999). In our previous work (Jian et al., 2001), it was indicated that the HSP60 gene may also be a useful tool for phylogenetic study of the genus Bifidobacterium. The clustering pattern was not only similar to that of $16 \mathrm{~S}$ rDNA, but there was also a better correlation with DNA G+C content. Furthermore, HSP60 gene sequence similarities $(\sim 84-96 \%)$ between Bifidobacterium species were much lower than those of $16 \mathrm{~S}$ rDNA.

To evaluate the feasibility of using HSP60 genes to identify Bifidobacterium species, 32 Bifidobacterium strains that represented eight species and subspecies were isolated from faeces of several kinds of animal (see supplementary material in IJSEM Online) by using Hungate's anaerobic roll-tube technique with TPYG (trypticase/peptone/yeast extract/glucose) medium (Scardovi, 1986). Gram-stain, anaerobic growth and catalase and fructose-6-phosphate phosphoketolase (F6PPK) activities were detected as described by Scardovi (1986). End-products of glucose fermentation were detected by GC using a model GC-14B chromatograph (Shimadzu). Biochemical characteristics were determined by using an API 50CH kit (bioMérieux). Temperature profiles were determined by using a water bath with a temperature gradient.

To confirm the identification of the 32 new isolates phylogenetically, DNA was prepared and purified as described by Marmur (1961) and 16S rDNA was amplified by PCR and sequenced by using ABI PRISM BigDye Terminator Cycle Sequencing Ready Reaction kits (PerkinElmer). The most similar 16S rDNA sequences in GenBank were found by searching with the BLAST program (version 2.2.1). Species identification and GenBank accession numbers of $16 \mathrm{~S}$ rDNA are available as supplementary material in IJSEM Online.

The partial HSP60 gene (600 bp) was amplified, cloned and sequenced as described previously (Jian et al., 2001). Partial HSP60 gene sequences were also translated into protein sequences by using the PRIMER PREMIER program, version 5.00 (Biosoft International). Methods for sequence similarity calculation and phylogenetic tree construction were described previously (Jian et al., 2001).

DNA G $+\mathrm{C}$ content was determined by thermal denaturation (Marmur \& Doty, 1962). DNA-DNA relatedness between the new isolates and reference strains was determined by using the reassociation rate method (Dong et al., 2000).

In this work, partial HSP60 genes were sequenced for 37 Bifidobacterium strains that represented 10 Bifidobacterium species, including two subspecies, with validly published names. HSP60 gene sequence homology was analysed totally for 50 bifidobacterial strains, including 12 type strains, and another Bifidobacterium infantis strain that was studied previously; a phylogenetic tree (Fig. 1) was constructed. The result showed that partial HSP60 gene sequence similarity was $96 \cdot 5-100 \%$ (mean, $98 \%$ ) among strains within a species, $95 \cdot 5-97 \%$ between Bifidobacterium pseudolongum subsp. pseudolongum JCM $1205^{\mathrm{T}}$ and nine strains of B. pseudolongum subsp. globosum and 80-96\% (mean, $88 \%$ ) among the 10 Bifidobacterium species in this study. The result was in agreement with the previous conclusion (Jian et al., 2001).

Noticeably, HSP60 gene sequence similarities were determined to be $98-100 \%$ among eight isolates of $B$. infantis, five isolates of B. longum and two isolates of Bifidobacterium suis, a similarity level equivalent to those within other Bifidobacterium species. Meanwhile, at 99\% HSP60 gene sequence similarity, these strains were clustered into three groups. The results supported the proposal to unify $B$. infantis, B. longum and B. suis into one species as three biotypes (Sakata et al., 2002), based on high 16S rDNA sequence similarities ( $\geqslant 99 \%$ ) among them.

An extremely high $16 \mathrm{~S}$ rDNA sequence similarity $(98 \cdot 8 \%)$ was also determined between Bifidobacterium lactis and Bifidobacterium animalis; Cai et al. (2000) proposed that $B$. lactis is a junior subjective synonym of $B$. animalis, based on this high 16S rDNA sequence similarity and high DNA-DNA hybridization $(85 \cdot 5-92 \cdot 3 \%)$ between the type strains of the two species. In the current study, high partial HSP60 sequence similarity was determined among five B. animalis and two B. lactis strains: $98 \cdot 9-100 \%$ within group 1 (including B. lactis DSM $10140^{\mathrm{T}}$, B. lactis JB- 1 and $B$. animalis B83) and group 2 (including $B$. animalis $\mathrm{JCM} 1190^{\mathrm{T}}, B$. animalis $\mathrm{D} 1, B$. animalis III-1 and $B$. animalis III-6); however, similarity levels ranged from $97 \cdot 0$ to $97 \cdot 8 \%$ between the two groups. Hence, B. lactis DSM $10140^{\mathrm{T}}$ and other B. lactis strains should be regarded as another subspecies of $B$. animalis, although they were genetically and phenotypically very similar to some $B$. animalis strains.

Partial HSP60 gene sequence similarity between five Bifidobacterium pseudocatenulatum and three B. catenulatum isolates (91-93\%) supported their interspecies relationship, although they had extremely high $16 \mathrm{~S}$ rDNA gene sequence similarity $(99 \cdot 5 \%)$.

Combining the results of this work and the previous study (Jian et al., 2001), a conclusion could be drawn that homology of the partial HSP60 gene of the bifidobacteria was $80-96 \%, 96 \cdot 5-100 \%$ and $95 \cdot 5-97 \%$ at the interspecies, intraspecies and inter-subspecies levels, respectively. Deduced HSP60 protein sequence similarities were $87-100 \%, 98 \cdot 5-100 \%$ and $98-100 \%$ at the interspecies, intraspecies and inter-subspecies levels, respectively. Compared to $16 \mathrm{~S}$ rDNA, the HSP60 gene has sufficient power for identification of Bifidobacterium species. 


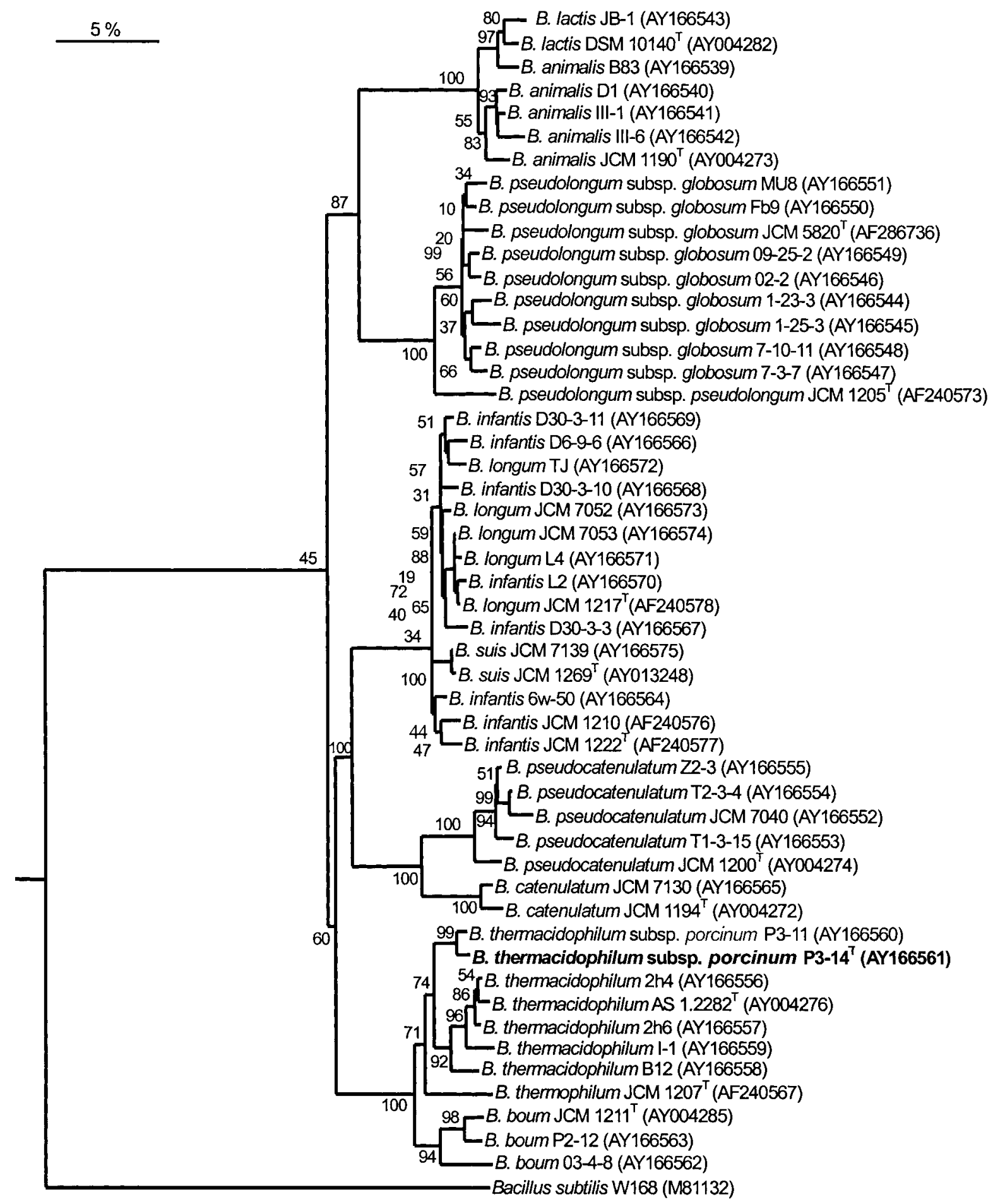

Fig. 1. Phylogenetic tree based on fragments (538 bp) of HSP60 gene DNA sequences. The tree was rooted with Bacillus subtilis W168 and constructed by using the Fitch method with bootstrap values calculated from 1000 trees. Numbers at each branch-point represent bootstrap support (\%); GenBank accession numbers of HSP60 gene sequences are given in parentheses. Bar, $5 \%$ sequence divergence.

Deduced HSP60 protein sequences showed $100 \%$ similarity among the thermophilic group that comprises B. boum, B. thermacidophilum and B. thermophilum, although interspecies DNA homologies were $92 \cdot 9-95 \cdot 5 \%$. Three signature amino acid residues at positions 156, 158 and 179 (Lys, Arg and Ser) differentiated this group 
from all other bifidobacteria (Asn, Lys and Thr) tested. Shared primary structures of HSP60 might relate to their thermophilic characteristics.

Based on HSP60 gene sequence similarities, two new isolates from piglet faeces, $\mathrm{P} 3-14^{\mathrm{T}}$ and $\mathrm{P} 3-11$, were identified as a novel subspecies of $B$. thermacidophilum. Similarities between strain $\mathrm{P} 3-14^{\mathrm{T}}$ and others were determined as follows: $97 \%$ with B. thermacidophilum AS $1.2282^{\mathrm{T}}$, $95 \cdot 5 \%$ with $B$. thermophilum JCM $1207^{\mathrm{T}}$ and $94 \cdot 4 \%$ with B. boum JCM $1211^{\mathrm{T}}$.

Homology analysis of the complete $16 \mathrm{~S}$ rDNA sequence (1523 bp) of $\mathrm{P} 3-14^{\mathrm{T}}$ also indicated its affiliation to the thermophilic bifidobacteria: B. boum ( $97 \cdot 7 \%$ similarity), $B$. thermacidophilum $(97 \cdot 2 \%$ similarity) and B. thermophilum (97.0\% similarity). Furthermore, DNA-DNA relatedness was determined to be $83 \cdot 0,58 \cdot 6$ and $25 \cdot 5 \%$ between isolate $\mathrm{P} 3-14^{\mathrm{T}}$ and $B$. thermacidophilum AS $1.2282^{\mathrm{T}}$, B. thermophilum JCM $1207^{\mathrm{T}}$ and B. boum JCM $1211^{\mathrm{T}}$, respectively, indicating that the new isolate belonged to $B$. thermacidophilum.

However, compared to B. thermacidophilum, strain P3-14 ${ }^{\mathrm{T}}$ grew at a relatively low temperature, as well as the fact that it fermented trehalose but not D-mannose, inulin or L-arabinose. Table 1 shows differential phenotypic characteristics of strain P3-14 $4^{\mathrm{T}}$, B. thermophilum JCM $1207^{\mathrm{T}}$, B. thermacidophilum AS $1.2282^{\mathrm{T}}$ and B. boum JCM $1211^{\mathrm{T}}$. Considering the relatively low 16S rDNA and HSP60 gene sequence similarities, different $\mathrm{G}+\mathrm{C}$ contents and fermentation patterns among them, as well as the lower growth temperature of $\mathrm{P} 3-14^{\mathrm{T}}$, a novel subspecies, Bifidobacterium thermacidophilum subsp. porcinum subsp. nov., is proposed. Accordingly, B. thermacidophilum is assigned as B. thermacidophilum subsp. thermacidophilum.

Table 1. Differential phenotypic characteristics of $B$. thermacidophilum subsp. porcinum subsp. nov., B. thermacidophilum, B. thermophilum and B. boum

Taxa: 1, B. thermacidophilum subsp. porcinum subsp. nov. P3-14 ${ }^{\mathrm{T}}$; 2, B. thermacidophilum AS $1.2282^{\mathrm{T}} ; 3$, B. thermophilum JCM $1207^{\mathrm{T}}$; 4, B. boum JCM $1211^{\mathrm{T}}$ [data from Scardovi et al. (1979)]. + , Positive reaction; -, negative reaction; $\mathrm{W}$, weak reaction; D, variable reaction.

\begin{tabular}{|lcccc|}
\hline Characteristic & $\mathbf{1}$ & $\mathbf{2}$ & $\mathbf{3}$ & $\mathbf{4}$ \\
\hline Fermentation of: & & & & \\
$\quad$ L-Arabinose & - & + & - & - \\
D-Mannose & - & + & - & - \\
Methyl $\alpha$-D-glucoside & $\mathrm{W}$ & + & $\mathrm{W}$ & \\
Inulin & - & + & $\mathrm{W}$ & $\mathrm{D}$ \\
Trehalose & + & - & - & $\mathrm{D}$ \\
Maximum growth temp $\left({ }^{\circ} \mathrm{C}\right)$ & $46 \cdot 5$ & $49 \cdot 5$ & 47 & 45 \\
Minimum growth pH & $4 \cdot 0$ & $4 \cdot 0$ & $4 \cdot 2$ & $>5 \cdot 0$ \\
DNA G+C content $(\mathrm{mol} \%)$ & $61 \cdot 5$ & $57 \cdot 7$ & 60 & 60 \\
\hline
\end{tabular}

\section{Emended description of Bifidobacterium thermacidophilum (Dong et al. 2000)}

Bifidobacterium thermacidophilum (therm.a.ci.do'phi.lum. Gr. n. therme heat; N.L. n. acidum acid; N.L. adj. philum from Gr. adj. philos loving; N.L. adj. thermacidophilum heat- and acid-loving).

Gram-positive, non-motile, non-spore-forming, irregular rods, $0 \cdot 5 \times 3-8 \mu \mathrm{m}$ in size after $12-24 \mathrm{~h}$ growth in TPYG medium at $37^{\circ} \mathrm{C}$; strictly anaerobic, no gas is formed from glucose. Optimum temperature for growth is $37-41^{\circ} \mathrm{C}$; temperature range for growth is $30-49.5^{\circ} \mathrm{C}$. Optimum initial $\mathrm{pH}$ is $7 \cdot 0-7 \cdot 2$, growth is quite good at $\mathrm{pH} 4.5$ but is delayed at $\mathrm{pH} 4 \cdot 0$. D-Fructose, galactose, D-glucose, maltose, melibiose, sucrose, D-raffinose, amidon, glycogen and D-turanose are fermented. Mannitol, rhamnose and sorbose are not fermented. Fermentation of L-arabinose, gluconate, inulin, lactose, D-mannose, methyl $\alpha$-Dglucoside, ribose, salicin, trehalose and xylose is variable. Litmus milk is not acidified or coagulated by most strains. Fermentation products from glucose are acetic and lactic acids, at a molar ratio of $2 \cdot 46-4 \cdot 9: 1$. DNA G $+\mathrm{C}$ content is $54 \cdot 8-61 \cdot 9 \mathrm{~mol} \%$.

\section{Description of Bifidobacterium thermacidophilum subsp. thermacidophilum subsp. nov.}

All strains meet the species description. Maximum temperature for growth is $49 \cdot 5^{\circ} \mathrm{C}$. L-Arabinose, inulin and D-mannose are fermented. Trehalose is not fermented. Fermentation products from glucose are acetic and lactic acids at a molar ratio of $2 \cdot 46-2 \cdot 72: 1$. DNA G $+\mathrm{C}$ content is $56 \cdot 85 \pm 2 \cdot 05 \mathrm{~mol} \%$.

The type strain, $36^{\mathrm{T}}\left(=\right.$ AS $\left.1.2282^{\mathrm{T}}=\mathrm{LMG} 21395^{\mathrm{T}}\right)$, was isolated from wastewater.

\section{Description of Bifidobacterium thermacidophilum subsp. porcinum subsp. nov.}

Bifidobacterium thermacidophilum subsp. porcinum (por. ci'num. L. neut. adj. porcinum of a hog).

All strains meet the species description. Maximum temperature for growth is $46.5^{\circ} \mathrm{C}$. Trehalose is fermented. L-Arabinose, inulin and D-mannose are not fermented. Fermentation products from glucose are acetic and lactic acids at a molar ratio of $4 \cdot 9: 1$. DNA $G+C$ content is $61 \cdot 2 \pm 0 \cdot 7 \mathrm{~mol} \%$.

The type strain, P3-14 ${ }^{\mathrm{T}}\left(=\right.$ AS $\left.1.3009^{\mathrm{T}}=\mathrm{LMG} 21689^{\mathrm{T}}\right)$, was isolated from the faeces of a piglet.

\section{Acknowledgements}

This study was supported by grants from the China National Foundation of Sciences (no. 3007001) and the Chinese Academy of Sciences. 


\section{References}

Biavati, B. \& Mattarelli, P. (1991). Bifidobacterium ruminantium sp. nov. and Bifidobacterium merycicum sp. nov. from the rumens of cattle. Int J Syst Bacteriol 41, 163-168.

Biavati, B., Mattarelli, P. \& Crociani, F. (1991). Bifidobacterium saeculare: a new species isolated from feces of rabbit. Syst Appl Microbiol 14, 389-392.

Cai, Y., Matsumoto, M. \& Benno, Y. (2000). Bifidobacterium lactis Meile et al. 1997 is a subjective synonym of Bifidobacterium animalis (Mitsuoka 1969) Scardovi and Trovatelli 1974. Microbiol Immunol 44, 815-820.

Crociani, F., Biavati, B., Alessandrini, A., Chiarini, C. \& Scardovi, V. (1996). Bifidobacterium inopinatum sp. nov. and Bifidobacterium denticolens sp. nov., two new species isolated from human dental caries. Int J Syst Bacteriol 46, 564-571.

Dong, X., Xin, Y., Jian, W., Liu, X. \& Ling, D. (2000). Bifidobacterium thermacidophilum sp. nov., isolated from an anaerobic digester. Int J Syst Evol Microbiol 50, 119-125.

Hoyles, L., Inganäs, E., Falsen, E., Drancourt, M., Weiss, N., McCartney, L. A. \& Collins, M. D. (2002). Bifidobacterium scardovii sp. nov., from human sources. Int J Syst Evol Microbiol 52, 995-999.

Jian, W. \& Dong, X. (2002). Transfer of Bifidobacterium inopinatum and Bifidobacterium denticolens to Scardovia inopinata gen. nov., comb. nov., and Parascardovia denticolens gen. nov., comb. nov., respectively. Int J Syst Evol Microbiol 52, 809-812.

Jian, W., Zhu, L. \& Dong, X. (2001). New approach to phylogenetic analysis of the genus Bifidobacterium based on partial HSP60 gene sequences. Int J Syst Evol Microbiol 51, 1633-1638.

Kwok, A. Y. C., Su, S.-C., Reynolds, R. P., Bay, S. J., Av-Gay, Y., Dovichi, N. J. \& Chow, A. W. (1999). Species identification and phylogenetic relationships based on partial HSP60 gene sequences within the genus Staphylococcus. Int J Syst Bacteriol 49, 1181-1192.

Lauer, E. (1990). Bifidobacterium gallicum sp. nov. isolated from human feces. Int J Syst Bacteriol 40, 100-102.

Lauer, E. \& Kandler, O. (1983). DNA-DNA homology, murein types and enzyme patterns in the type strains of the genus Bifidobacterium. Syst Appl Microbiol 4, 42-64.

Marmur, J. (1961). A procedure for the isolation of deoxyribonucleic acid from microorganisms. J Mol Biol 3, 208-218.
Marmur, J. \& Doty, P. (1962). Determination of the base composition of deoxyribonucleic acid from its thermal denaturation temperature. J Mol Biol 5, 109-118.

Marston, E. L., Sumner, J. W. \& Regnery, R. L. (1999). Evaluation of intraspecies genetic variation within the $60 \mathrm{kDa}$ heat-shock protein gene (groEL) of Bartonella species. Int J Syst Bacteriol 49, 1015-1023.

Meile, L., Ludwig, W., Rueger, U., Gut, C., Kaufmann, P., Dasen, G., Wenger, S. \& Teuber, M. (1997). Bifidobacterium lactis sp. nov., a moderately oxygen tolerant species isolated from fermented milk. Syst Appl Microbiol 20, 57-64.

Miyake, T., Watanabe, K., Watanabe, T. \& Oyaizu, H. (1998). Phylogenetic analysis of the genus Bifidobacterium and related genera based on 16S rDNA sequences. Microbiol Immunol 42, 661-667.

Olsen, G. J., Woese, C. R. \& Overbeek, R. (1994). The winds of (evolutionary) change: breathing new life into microbiology. $J$ Bacteriol 176, 1-6.

Requena, T., Burton, J., Matsuki, T., Munro, K., Simon, M. A., Tanaka, R., Watanabe, K. \& Tannock, G. W. (2002). Identification, detection, and enumeration of human Bifidobacterium species by PCR targeting the transaldolase gene. Appl Environ Microbiol 68, 2420-2427.

Roy, D. \& Ward, P. (1990). Evaluation of rapid methods for differentiation of Bifidobacterium species. J Appl Bacteriol 69, 738749.

Sakata, S., Kitahara, M., Sakamoto, M., Hayashi, H., Fukuyama, M. \& Benno, Y. (2002). Unification of Bifidobacterium infantis and Bifidobacterium suis as Bifidobacterium longum. Int J Syst Evol Microbiol 52, 1945-1951.

Scardovi, V. (1986). Genus Bifidobacterium Orla-Jensen. In Bergey's Manual of Systematic Bacteriology, vol. 2, pp. 1418-1434. Edited by P. H. A. Sneath, N. S. Mair, M. E. Sharpe \& J. G. Holt. Baltimore: Williams \& Wilkins.

Scardovi, V., Trovatelli, L. D., Biavati, B. \& Zani, G. (1979). Bifidobacterium cuniculi, Bifidobacterium choerinum, Bifidobacterium boum, and Bifidobacterium pseudocatenulatum: four new species and their deoxyribonucleic acid homology relationships. Int $J$ Syst Bacteriol 29, 291-311.

Stackebrandt, E. \& Goebel, B. M. (1994). Taxonomic note: a place for DNA-DNA reassociation and 16S rRNA sequence analysis in the present species definition in bacteriology. Int $J$ Syst Bacteriol 44, 846-849. 